\title{
Apropriação da cidade enquanto experiência cenográfica e embate contra a ditadura militar: Na selva das cidades (Teatro Oficina e Lina Bo Bardi, 1969)
}

\author{
Patricia Morales Bertucci
}

Doutora em Artes CÊNicas da ECA-USP

Na selva das cidades propôs uma experiência cênica inovadora para a sua época, pois interveio no espaço simbólico do bairro do Bixiga, a contrapelo da produção do espaço autoritário da ditadura militar, em pleno Ato Institucional $\mathrm{n}^{\mathrm{o}} 5$. Pode-se considerar a peça como um ato de oposição e crítica à construção dos viadutos da Ligação Leste-Oeste, que rasgou o tecido urbano do local, sede do

${ }^{\mathrm{I}} \mathrm{O}$ texto Na selva das cidades, de Bertolt Brecht, foi encenado durante o AI-5, um dos períodos mais duros do regime, em que houve a cassação das liberdades civis, entre eles o direito de ir e vir na cidade. Mas a intimidação militar foi um estopim para o Teatro Oficina, que encenou algumas de suas peças mais icônicas naquela época: O rei da vela (1967), Roda viva (1968), Galileu Galilei (1968), Na selva das cidades (1969), Gracias Señor (1972) e As três irmãs (19721973). Entretanto, com o acirramento da violência, o grupo partiu para o exílio (1974-1978). A censura perseguiu o grupo desde 1968, quando atores do Teatro Oficina foram espancados pelo Comando de Caça aos Comunistas, enquanto faziam a peça Roda viva. Em 1974, uma invasão policial no Teatro Oficina prendeu seis pessoas, entre integrantes e frequentadores, sob a acusa- 
grupo até os dias de hoje. Tanto o projeto cenográfico de Lina Bo Bardi, quanto a encenação do texto de Bertolt Brecht por José Celso Martinez e os atores do Teatro Oficina, se apropriou dos escombros das demolições e desapropriações levadas a cabo pelo Estado para criar a poética espacial e dramatúrgica do espetáculo, em um período de intensificação dos conflitos sociais e políticos. Justifico tal afirmação baseada em dois pontos principais: primeiro, ao identificar que a ação do grupo estabeleceu um diálogo com os aspectos materiais e simbólicos do espaço do bairro, isto é, com os usos e funcionalidades do entorno, assim como a sua dimensão histórica, simbólica e arquitetônica; segundo, porque eles criaram tensões naquele ambiente, revelando as contradições ali presentes, com isso fizeram emergir os aspectos subterrâneos do poder ditatorial.

Como pode ser lido abaixo, na entrevista de José Celso Martinez, Na selva das cidades (1969) foi uma intervenção no espaço simbólico do bairro do Bixiga, pois a arquiteta Lina Bo Bardi se apropriou dos objetos abandonados pelos antigos moradores dos cortiços desocupados pelo Estado, dos restos das demoliçóes e do material de construção da Ligação Leste-Oeste no entorno do Teatro Oficina. Com isso, o grupo transformou a materialidade urbana em linguagem, o que considero como uma forma artística crítica de oposição simbólica da dominação do espaço pela ditadura.

[o Bexiga] era um bairro fantástico, marginal. Tinha milhões de bocas, uma marginália incrível! Um mundo de cortiços, rasgados de repente por esse Minhocão, esse viaduto que partiu as ruas ao meio e devastou tudo... me dava a sensação de que o que acontecia com o mundo, com a gente, acontecia também naquele bairro lá, que

ção de tráfico de drogas. Com o acirramento do cerco da censura ditatorial, Zé Celso publica o texto S.O.S. em que retoma a história do grupo e pede a soltura dos presos. Logo após a publicação do texto, em 22 de maio de 1974, Zé Celso, sua irmã Maria do Rosário Martinez Corrêa, o cineasta Celso Lucas e a empregada doméstica Maria de Lourdes são sequestrados pela polícia e levados pelo Departamento de Ordem Política e Social (Dops) de São Paulo. Em 17 de junho de 1974, Zé Celso é solto e parte para o exílio em Portugal, com mais quinze integrantes do Teatro Oficina (PECORELLI FILHO, Biagio. A pulsão performativa de Jaceguai: aproximações e distanciamentos entre o campo artístico da performance e a prática cênica do Teat(r)o Oficina nos espetáculos Macumba Antropófaga e Acordes. São Paulo, 2014 [Dissertação de Mestrado defendida na Universidade de São Paulo], p. 54). 
estava sendo entulhado de lixo. (...) Então tinha aquele lixo lá no Bexiga sendo removido, e aliás sendo substituído por um outro: o Minhocão, que passa hoje em frente à porta do teatro. E tinha o lixo de dentro do teatro também: a Lina Bardi, que fazia a cenografia da Selva, pegava o lixo do Bexiga e trazia para o palco. Tanto que a gente não pagou quase nada para o cenário. Ela saía feito doida no meio da rua: "Que bonito! Que maravilha!" Os maquinistas pensavam que a mulher estava maluca; ela catava o que havia de mais sórdido, triava e botava no cenário $2^{2}$

A construção da Ligação Leste-Oeste $\left.\right|^{3}$ foi uma das obras de transformação urbana mais polêmicas levadas a cabo pela ditadura militar por diversos motivos, entre eles: desalojou muitas famílias que moravam nos cortiços da região e estas, sem ter condiçóes de pagar por moradia no centro, foram morar em áreas periféricas; operou um corte radical no tecido urbano de um bairro de importância histórica e arquitetônica; priorizou o transporte individual sobre rodas, em detrimento do coletivo. Apenas por esses pontos já se pode entender que o complexo projetado em 1968 pelo prefeito Faria Lima (1965-1969) e implantado pelo prefeito Paulo Maluf (1969-197I) de forma apressada, ampliou as desigualdades e a segregação na cidade.

Maluf queria o mérito da inauguração para a sua gestão, pois planejava o cargo de governador o Estado - e conseguiu alguns anos depois, graças a localização privilegiada do viaduto e a sua propaganda (1979-1982) -, por isso a inauguração do "Minhocão" ocorreu no aniversário da cidade, em I97I, e a Prefeitura publicou um convite nos principais jornais convidando os paulistanos. No entanto, a obra

${ }^{2}$ CORRÊA; Z.C.M. "Dom José de la Mancha”, entrevista a Milton Almeida Filho. In: Primeiro ato: Cadernos, depoimentos, entrevistas (1958-1974). São Paulo: Ed.34., 1998, p. 168. Apud WISNIK, Guilherme. Dentro do nevoeiro: diálogos cruzados entre arte e arquitetura contemporânea. São Paulo, 2012 [Tese de Doutorado defendida na Universidade de São Paulo], p. 97.

3 Um complexo viário que recebe diversos nomes ao longo de sua extensão: Viaduto do Glicério, Avenida Radial Leste-Oeste, Viaduto Jaceguai, Viaduto Júlio de Mesquita, Praça Roosevelt e termina com o início do Elevado Presidente João Goulart, antigo Elevado Presidente Costa e Silva, mais conhecido como "Minhocão". 
do complexo ainda não tinha sido concluída, e só o foi anos depois. O convite homenageava o Presidente Costa e Silva (1967-1969), e o descrevia como "uma das grandes figuras da Revolução de 1964". Entretanto, assim que Costa e Silva assumiu a presidência, intensificou os atos de repressão policial-militar contra todos os movimentos, grupos e focos de oposição política. Ele também avançou o processo de institucionalização da ditadura e eliminou o que restava das liberdades políticas e democráticas do país com a instauração do Ato Institucional $\mathrm{n}^{\circ} \mathrm{s}$ (1968). Felizmente, o nome do viaduto foi alterado, em 2oı6, para Presidente João Goulart (196I-1964) graças ao programa "Ruas de Memória” da Secretaria Municipal de Direitos Humanos e Cidadania da Prefeitura de São Paulo. A mudança de nome do viaduto foi uma reparação histórica, pois um agente do Estado que praticou violaçóes de direitos humanos, envolvido com a ditadura militar, não pode ser lembrado como herói nos espaços públicos. O novo homenageado, o Presidente João Goulart foi deposto pelo golpe militar em 1964 e mesmo exilado no Uruguai, Goulart fez parte do movimento Frente Ampla, um dos grupos de oposição ao regime, composto por políticos influentes. Esse movimento pressionou o governo reivindicando anistia, uma assembleia constituinte e eleiçôes diretas para governador de Estado e presidente da República as suas lideranças políticas procuraram também obter o apoio popular articulando-se aos sindicatos trabalhistas.

Uma intervenção viária como a da Ligação Leste-Oeste era algo que já tinha provado a sua ineficiência nos Estados Unidos, por exemplo, como defendeu a jornalista militante Jane Jacobs, no livro Morte e vida de grandes cidades (196I), pois potencialmente degradante para o tecido urbano e, principalmente, para os habitantes do seu entorno. Jacobs já criticava duramente esse tipo de transformação urbana que aconteceu nos Estados Unidos, na década de 1950, ela ficou conhecida por organizar mobilizaçóes de base no seu bairro. As mobilizaçôes da jornalista eram para proteger o bairro de Greenwich Village dos grandes complexos viários planejados por Robert Moses. Moses foi um dos grandes entusiastas das vias expressas e pontes. Entre 1938 e 1964, trabalhou na implantação de diversas delas, e foi responsável por devastar grandes setores consolidados da cidade de Nova York. Marshall Berman considera que Moses abriu "seu mundo da via expressa 
através das cidades, eliminando todo traço de vida que aí existia antes", ${ }_{4}^{4}$

Tendo em vista a implantação desse tipo de construção ineficiente e degradante para o tecido urbano e, principalmente, para os habitantes do seu entorno, entendo que $\mathrm{Na}$ selva das cidades estabeleceu um diálogo com os aspectos materiais e simbólicos do espaço do bairro. Lina trouxe para dentro do teatro tudo o que havia sobrado do Bixiga para ser reprocessado pelos atores durante a encenação do espetáculo. Dia a dia, o cenário era construído e destruído, assim como o que ocorria na cidade, fora do teatro, que se tornava a sua extensão. Além dos entulhos e objetos dos antigos habitantes do bairro, os elementos fixos do projeto cênico eram duas plateias opostas a um ringue de boxe, uma betoneira (que funcionava em cena), peixes mortos macerados diuturnamente, e frases e faixas com mensagens correntes na propaganda militar.

Entendo que esse projeto cênico do Teatro Oficina estava alinhado ao momento histórico e artístico internacional, a chamada virada performativa, quando vieram à tona inovaçôes estéticas e ideológicas do campo do teatro, responsáveis por colocar os corpos dos artistas e do público no centro de reflexão/ação da obra de arte. Virada performativa é um termo cunhado pela pesquisadora alemã Fischer-Lichte, no livro The transformative power of performance (2008), diferente da corrente americana dos estudos da performance, baseada em Richard Schechner, pois se coloca além das dicotomias que firmaram a performance em franca oposição ao teatro, como pode ser lido no livro The Show and the Gaze of Theatre (1997). Fischer-Lichte afirma que o caráter autorreferencial e constitutivo de realidade do performativo, com referência a J.L. Austin, mais especificamente ao texto How to do things with words:

(...) se você considera o ato da fala, por exemplo, "Eu vos declaro marido e mulher”, essas são palavras executando o que é dito, isso é autorreferencialidade; elas não se referem a algo fora, elas estão executando exatamente aquilo que elas dizem. Está implícito que o padre tem o poder de fazer isso, "Eu vos declaro marido e mulher", então está feito. E, portanto, é constitutivo de uma nova realidade

${ }^{4}$ BERMAN, Marshall. Tudo que é sólido desmancha no ar: a aventura da modernidade. São Paulo: Companhia das Letras, 2005. 
social; eles agora estão casados, têm certos direitos e deveres. Isso é muito importante sobre o conceito desenvolvido por Austin - a língua não é algo que descreve certos estados e processos que possam acontecer, mas a língua, por si mesma, tem o poder de agir. Equando ela age, uma nova realidade social surg $\rfloor^{5}$

Logo, a potência do ato performativo estaria na sua própria forma, na linguagem como ato transformador.

O que Fischer-Lichte denomina virada performativa, pode ser alinhado ao que Fredric Jameson considera como um movimento de inovação nas artes impulsionado pela convicção de que a arte seria uma forma de práxis - crença de que as mudanças no campo da arte também contribuiriam para mudar a vida, até nas ações mais estetizantes ou menos conscientes do ponto de vista político. Jameson se refere aos Estados Unidos, quando a inovação teatral foi encenada como "um gesto simbólico de protesto estético", 6 algo que pode ser identificado no Living Theatre 7 e também no Teatro Oficina, que estiveram em contato direto. Em 1970, logo após Na selva das cidades, o Oficina convidou para vir ao Brasil o Living Theatre para partilhar o seu processo criativo, a experiência não resultou em um espetáculo em comum, mas foi uma troca no sentido do anseio radical de fusão entre arte e vida. Como afirma Zé Celso:

O Living Theatre - considerado um dos grupos mais importantes da vanguarda mundial - chegava ao Brasil, a convite do Oficina, para

s FISCHER-LICHTE; in: FISCHER-LICHTE, Erika; BONFITO, Matteo. "Entrevista com Erika Fischer Lichte”. In: Conceição/Conception. Campinas, SP, v. 2, n. I, pp. I3I-I4I, jan./jun. 20I3, p. I3I.

'JAMESON, Fredric. “'End of Art' or 'end of History”. In: The cultural turn: selected writings on the postmodern 1983-1998. Londres /Nova York: Verso, 1998, p. 75.

7 Um dos espetáculos mais importantes do Living Theatre foi Paradise now, obra referência para história da arte da performance. O encontro dos grupos foi primordial para a criação do espetáculo Gracias Señor pelo Teatro Oficina, tendo em vista os traços em comum entre o espetáculo e a programática política contracultural europeia e americana dos anos 1960. (PECORELLI FILHO, Biagio. A pulsão performativa de Jaceguai: aproximaçóes e distanciamentos entre o campo artístico da performance e a prática cênica do Teat(r)o Oficina nos espetáculos Macumba Antropófaga e Acordes.: São Paulo, 2014 [Dissertação de Mestrado defendida na Universidade de São Paulo], p. 49). 
o trabalho conjunto com o grupo paulista. A convivência durou três meses e levou José Celso a uma segura conclusão: ambos os grupos, mesmo influenciando-se mutuamente, perseguiam objetivos diferentes e inconciliáveis. (...) Da rápida união, o Oficina soube tirar lições. Mastigou-as em silêncio durante algum tempo até decidir: no asfalto paulistano, elas não poderiam germinar. E decidiu levar sua bigorna a recantos onde seu timbre pudesse ainda ecoar. Era preciso esquecer os anos de sucesso e humildemente retornar ao marco zero de uma nova estrada 8

Neste sentido, considero que o Teatro Oficina fez parte do movimento internacional de inovação nas artes, mas diferente da ideia jamesoniana de retomada das vanguardas, dado o seu contexto de atuação, mais distópico do que utópico, pois no período mais duro da ditadura militar, além da sua pauta tropicalista. Celso Favaretto, por exemplo, define a tropicália como uma macroimagem que buscava entender o estado assíncrono do país, a convivência do mais avançado com o mais atrasado, isto é, do arcaico com moderno, de modo que nenhum devoraria o outro, eles se entredevoram e permanecem ambos ativos. Para ele, isso poderia ser identificado naquela ocasião tanto em Terra em transe de Glauber Rocha, no livro PanAmérica de José Agrippino, na instalação Tropicália de Hélio Oiticica e na música de Caetano Veloso com o mesmo nome. Ou seja, diferentemente da utopia das vanguardas históricas, o arcaico e o moderno não passam pelo esquema da superação no Brasil. .9 Aqui os arcaísmos e as modernizações estão não apenas em combate, estão numa relação de indissolubilidade e não se aponta nenhuma solução para isso, como pode ser lido no texto "Brasil diarreia” de Hélio Oiticica. Para Oiticica, o Brasil estaria sempre excretando coisas, antigas e modernas, e isso não se resolveria, é como numa doença, a doença do conservadorismo que se mistura aos elementos modernizadores e avançados..$^{10}$

\footnotetext{
${ }^{8}$ PENIDO, Gandara. As promessas do Oficina. In: Revista Veja. São Paulo: Abril, n. I72, 22 dez. 197I, p. 98.

${ }^{9}$ Cf. FAVARETTO, Celso Fernando. A Invenção de Hélio Oiticica. São Paulo: Editora da Universidade de São Paulo, 2oIs.

ro OITICICA, Hélio. "Brasil Diarreia". In: Arte brasileira contemporânea. Caderno de Textos i: O Moderno e o Contemporâneo (o novo e o outro novo). Rio de Janeiro: Funarte, I980, pp. 26-27.
} 
Neste contexto, a minha hipótese é que o projeto cênico de Na selva das cidades se apropriou do bairro, enquanto extensão do teatro, trazendo para a cena as tensões existentes naquele ambiente urbano e revelando as contradições ali presentes. Com isso, emergiram aspectos simbólicos desde a produção do espaço implementado pelo projeto urbano ditatorial. O que se articula com a arte tropicalista, já que um operador para o artista, que se apropriou dos elementos contraditórios produzidos pelo que Oiticica chama de "diarreia brasileira", ciente da sua relação de indissolubilidade. Ou seja, o projeto cênico de Lina, dialogou com a produção do espaço simbólico do bairro do Bixiga, para destacar as contradições eminentes daquele contexto urbano. Na selva das cidades se apropriou das ruínas da modernidade, ou em outras palavras, dos restos das obras no bairro do Bixiga e entrou em embate com a ideologia progressista dos militares ao destacar os problemas causados pela construção que estava em andamento.

O projeto cenográfico de Lina destacou a distopia do contexto urbano da época, representando uma organização social caracterizada por condições de vida "desumanizada", com o objetivo de criticar tendências da sociedade daquele período e de parodiar a questão da utopia ditatorial, em alerta aos seus perigos. Refiro-me a distopia aqui com referência no livro Eclipse da razão de Max Horkheimer. Neste livro, escrito durante a segunda guerra, em meados dos anos 1940, após o autor presenciar as barbáries do nazismo e do fascismo, Horkheimer investigou as transformações que ocorreram na sociedade com o advento da industrialização, como o predomínio da técnica. Por exemplo, o predomínio da razão subjetiva em detrimento da razão objetiva. A razão objetiva, segundo o autor, teria como ênfase conceitos como a "ideia do bem supremo, o problema do destino humano e o modo de realização dos fins últimos” [m Em contrapartida, a razão subjetiva, diz ele, relaciona-se essencialmente com meios e fins, "com a adequação de procedimentos mais ou menos tidos como certos e que se presumem autoexplicativos. [A razão subjetiva] Concede pouca importância à indagação de se os propósitos como tais são racionais" [2 O predomínio da razão subjetiva após os avanços dos meios técnicos condiciona o pensamento a um simples instrumento, orientado por valores utilitários imediatos, assim como

\footnotetext{
${ }^{\text {II }}$ HORKHEIMER, M. Eclipse da razão. Rio de Janeiro: Ed. Labor, 1976, p. I3.

${ }^{12}$ Ibid., pp. II-I2.
} 
ocorreu em São Paulo durante a ditadura, pois em regimes de exceção os avanços do esclarecimento dos meios técnicos geralmente são acompanhados por um processo de desumanização.

Nesses termos, a encenação de Na selva das cidades destacou esse processo de desumanização, como podia ser visto nas paredes rabiscadas no interior do teatro ou na faixa sobre o palco: "A São Paulo, a cidade que se humaniza", um dos slogans oficiais do governo militar divulgado nas ruas por outdoor e nas mídias impressas, como publicado na revista Manchete sobre a inauguração da Praça Roosevelt, um ano depois da peça:

Pela audácia de sua concepção arquitetônica, a Praça Roosevelt é um resumo da nova São Paulo. Uma praça de quatro andares, única no mundo, como única no mundo é a metrópole paulista. Em São Paulo, o futuro foi antecipado pelas obras, que conseguiram o milagre de engrandecê-la e torná-la mais humana, porque foram feitas com as vistas voltadas para o homem.

A interpretação de Zé Celso na direção do espetáculo teatral é atravessada pela pergunta: um indivíduo conseguiria ser fiel às suas crenças enquanto o caos predomina em sua volta?

SHLINK com ingenuidade - É preciso saber o que é mais importante: um quilo de peixe ou uma opinião. Ou ainda: dois quilos de peixe ou uma opinião

Por isso, ele propôs que os atores dialogassem com a materialidade do espaço social trazida para dentro do palco. Os atores atacavam o cenário durante a encenação, era como se aquele material representasse a violência dos militares contra o espaço e o corpo dos cidadãos. Assim, eles discutiam sobre o empobrecimento do cotidiano da vida pelo capital que entrava na sua nova fase pós-segunda guerra:

${ }^{13}$ Disponível em: https://quandoacidade.wordpress.com/2013/03/14/mais-o-que/. Acesso em: 23 nov. 202I.

${ }^{14}$ BRECHT, Bertolt. Teatro completo em I2 volumes. V. 2. Rio de Janeiro: Paz e Terra, I987, p. I4. 
"Não podíamos ser piedosos conosco", registrou a principal atriz do elenco Ítala Nandi, sobre o espetáculo que para ela "surgia para denunciar a opressão urbana sobre o homem" como um ato de resistência poética: "era um grito de socorro - em muitos momentos até conformado - mostrando uma grande impotência frente a uma realidade tão dura"

O público também era incorporado à ambiência de caos da peça, afinal o diretor José Celso Martinez visava muito mais propiciar uma vivência ampla que produzir um simples espetáculo visual, o que para o crítico Edelcio Mostaço se dá pela técnica de encenação usada na montagem, o environmental theatre (teatro ambiental):

No eixo primário temos o árduo trabalho corporal e a intensa troca de energias entre os intérpretes (...). No segundo, as relações mostravam-se ainda mais implementadas: a arquitetura cênica conformava um espaço ritual aberto às interações entre dispositivos, inclusive com deslocamento dos intérpretes e do público; o que reforçava, a todo o momento, o manuseio não apenas de objetos e apetrechos cênicos como seu uso disseminado pela totalidade do espaço cênico; atingindo desse modo uma pletora funcional, visual e material. ${ }^{16}$

$\mathrm{O}$ environment theatre tem como princípio o envolvimento ativo entre todos os aspectos da representação durante a encenação: o tempo, o espaço, os atores e os espectadores. No teatro ambiental, o espaço é usado sem limitações, em um jogo que tanto atores quanto espectadores precisam saber lidar com esse espaço sem fronteiras ${ }^{17}$ Entretanto, acredito que a encenação do grupo podia até ter influência da técnica teatral criada por Richard Schechner em 1967, enquanto era diretor do The performance group em Nova York, mas se alinhava aos procedimentos do tropicalismo, como apontei acima.

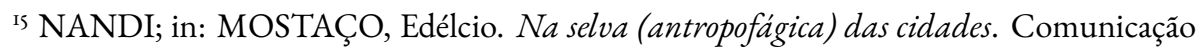
apresentada no Simpósio Nacional De História ANPUH - XXV, Fortaleza, 2009, p. 2.

${ }^{16}$ Ibid. pp. 7-8.

${ }^{17}$ Cf. SCHECHNER, Richard. Environmental theatre: an expanded new edition. Nova York: Applause, 1973 . 
O texto Na selva das cidades pertence à primeira fase de Brecht, pois foi escrita entre I92I-I923, e mostra um autor questionador e anárquico, que traz em seus textos cenários de fome, miséria e desespero ${ }^{18}$ esse em específico trata do êxodo rural vivido por famílias que procuravam trabalho e estabilidade social na vida urbana e a primeira obra do autor a ter como pano de fundo o sonho americano materializado em suas cidades:

Os senhores estão em Chicago, no ano de I9I2. Vão ver a inexplicável luta entre dois homens e assistir à decadência de uma família que veio do campo para a selva da grande cidade. Não quebrem a cabeça para descobrir os motivos dessa luta, mas procurem participar das jogadas humanas. Julguem com imparcialidade os métodos de luta dos adversários e dirijam o seu interesse para o "round" fina $\left.\right|^{19}$

A comparação social entre Chicago e São Paulo foi evidenciada pela encenação do Oficina, afinal, o bairro do Bixiga era composto inicialmente por imigrantes e depois por migrantes do Norte e Nordeste, que vieram em busca de melhores condiçôes de vida. Do ponto de vista urbanístico as cidades tinham em comum o modelo da "Highway" do americano trazido para o Brasil, para adaptar a cidade ao desenvolvimento da indústria automobilística, reproduzindo o american way of life. A Ligação Leste-Oeste é um exemplo disso.

Portanto, Na selva das cidades foi um ato de resistência poética ao futuro planejado pela ditadura que, estava alinhado às forças político-sociais que constituíram um novo cotidiano funcional a partir dos anos 1950 e 1960, como parte da reconstrução da economia após a segunda guerra mundial. A razão operatória usada na organização do cotidiano pela burguesia foi a expansão do consumo e as forças políticas e sociais convergiram para consolidar sua funcionalidade, muito diferente do futuro de criação proposto pelo grupo do Teatro Oficina, guiado pela invenção. Sendo assim, diferentemente do ideário utópico (lugar ou estado ideal, de completa felicidade e harmonia entre os indivíduos) o procedimento de

\footnotetext{
${ }^{18}$ Cf. KOUDELA, Ingrid. Brecht: um jogo de aprendizagem. São Paulo: Perspectiva, I99I.

I9 BRECHT, Bertolt. Teatro completo em I2 volumes. V. 2. Rio de Janeiro: Paz e Terra, I987,
} p. II. 
apropriação tropicalista criou contradições, capazes de nos levar além do bloqueio de imaginação histórica, como Jameson defende ${ }^{20}$ Concluo com a ideia de que o Oficina, a partir de sua virada performativa nos anos 1968, fez da linguagem um ato transformador, ao responder com poesia e desejo em oposição a um contexto de violência e dominação.

\section{Referências}

ARAÚJO, Antonio. Açôes disruptivas no espaço urbano. ABRACE Digital [online], pp. I-6, 2011.

BERMAN, Marshall. Tudo que é sólido desmancha no ar: a aventura da modernidade. São Paulo: Companhia das Letras, 2005.

BRECHT, Bertolt. Teatro completo em I2 volumes. V. 2. Rio de Janeiro: Paz e Terra, 1987.

FAVARETTO, Celso Fernando. A Invenção de Hélio Oiticica. São Paulo: Editora da Universidade de São Paulo, 2015.

FISCHER-LICHTE, Erika. The show and the gaze of the theatre. Iowa City: Iowa University Press, 1997.

. The transformative power of performance: a new aesthetics. Nova York: Routledge, 2008.

FISCHER-LICHTE, Erika; BONFITTO, Matteo. "Entrevista com Erika Fischer Lichte”. In: Conceição/Conception. Campinas, SP, v. 2, n. I, p. I3I-I4I, jan./jun. 20I3.

HORKHEIMER, M. Eclipse da razão. Rio de Janeiro: Ed. Labor, 1976.

JACOBS, Jane. Morte e vida de grandes cidades. São Paulo: Editora WMF Martins Fontes, 20II.

JAMESON, Fredric. "'End of Art' or 'end of History"”. In: The cultural turn: selected writings on the postmodern 1983-1998. Londres /Nova York: Verso, 1998.

KOUDELA, Ingrid. Brecht: um jogo de aprendizagem. São Paulo: Perspectiva, I99I.

\footnotetext{
${ }^{20}$ Op. cit., pp. 90-9I.
} 
MOSTAÇO, Edélcio. Na selva (antropofágica) das cidades. Comunicação apresentada no Simpósio Nacional De História ANPUH - XXV, Fortaleza, 2009. PENIDO, Gandara. As promessas do Oficina. Revista Veja. São Paulo: Abril, n. I72, 22 dez. 197I.

PECORELLI FILHO, Biagio. A pulsão performativa de Jaceguai: aproximações e distanciamentos entre o campo artístico da performance e a prática cênica do Teat(r)o Oficina nos espetáculos Macumba Antropófaga e Acordes. São Paulo, 2014 [Dissertação de Mestrado defendida na Universidade de São Paulo].

OITICICA, Hélio. "Brasil Diarreia”. In: Arte brasileira contemporânea. Caderno de Textos i: O Moderno e o Contemporâneo (o novo e o outro novo). Rio de Janeiro: Funarte, 1980, pp. 26-27.

SCHECHNER, Richard. Environmental theatre: an expanded new edition. Nova York: Applause, 1973.

WISNIK, Guilherme. Dentro do nevoeiro: diálogos cruzados entre arte e arquitetura contemporânea. São Paulo, 2oız [Tese de Doutorado defendida na Universidade de São Paulo].

Resumo: O grupo do Teatro Oficina foi bastante afetado pela construção do complexo viário da Ligação Leste-Oeste, localizado na Rua Jaceguai, no bairro do Bixiga, em São Paulo. O grupo resistiu a essa violenta transformação urbana que rasgou o bairro e se opôs às demolições e desapropriaçôes promovidas pelo Estado com a encenação da peça Na selva das cidades (1969), em uma época em que os poucos que se colocavam contra a ditadura sofreram sérias consequências. Tendo em vista tal contexto de intensificação dos conflitos sociais e políticos na cidade, discorro neste artigo sobre a experiên-
Abstract: The group Teatro Oficina was heavily affected by the construction of the East-West Link Road complex, located on Jaceguai Street, in the Bixiga neighbourhood of São Paulo. The group resisted this violent urban transformation that tore the neighbourhood, and they opposed the demolitions and expropriations promoted by the State performing the play "In the Jungle of Cities" (1969), during a time when those who stood against the dictatorship suffered serious consequences. Given this context of intensified social and political conflicts in the city, I discuss in this article 
cia cênica do espetáculo teatral que se about the scenic experience of the play apropriou dos escombros do bairro do that appropriated the rubble of the $\mathrm{Bi}$ Bixiga e desviou a produção simbólica xiga neighbourhood and diverted the do espaço da cidade, a contrapelo da symbolic production of the city's space, ditadura militar que implantava seu o against the military dictatorship that plano de transformação urbana e ideológica autoritária.

Palavras-chave: Experiência cenográfica; Espaço simbólico; Transformação Urbana; Apropriação da cidade; Ditadura Militar. implanted a plan of authoritarian urban and ideological transformation.

KEYwORDS: Scenographic experience; Symbolic space; Urban transformation; Appropriation of the city; Military Dictatorship. 